\title{
ANALISIS PENGGUNAAN DRIVER MINI VICTOR L298N TERHADAP MOBIL ROBOT DENGAN DUA PERINTAH ANDROID DAN ARDUINO NANO
}

\author{
${ }^{1 *}$ Muhammad Amin, ${ }^{1}$ Ricki Ananda, ${ }^{1}$ Juna Eska \\ Sistem Komputer, STMIK Royal Kisaran \\ Email: "stmikroyal13@gmail.com, rickianandainterface@ gmail.com
}

\begin{abstract}
Abstact: A robot is a set of mechanical devices or shaped vehicles that can perform physical tasks, both with human supervision and control, in the form of programs that have been defined in advance. Robot cars designed by researchers, use two commands to perform physical tasks. First use the command from Google Voice, which is the command with voice, and the second uses the command using the Android button, so that access to the robot can be done by anyone and anywhere. The work system of the robot car design is designed, when the robot car commands, the command will be juxtaposed or compared, and when the data is compared according to the data being controlled, the system will run according to the data or command earlier. For each module, it uses a voltage of $5 \mathrm{~V}$, while for a DC motor, it uses an external voltage of 7.4 VDC.
\end{abstract}

Keyword: Robot car, Arduino controller, Google voice.

Abstrak: Robot merupakan seperangkat alat mekanik atau berbentuk kendaraan yang bisa melakukan tugas fisik, baik dengan pengawasan dan kontrol manusia, berupa program yang telah didefisinikan terlebih dahulu. Mobil robot yang dirancang peneliti, menggunakan dua perintah untuk melakukan tugas fisik. Pertama menggunakan perintah dari google voice, yaitu perintah dengan suara, dan yang kedua menggunakan perintah menggunakan tombol button android, sehingga akses untuk memerinta robot dapat dilakukan oleh siapa saja dan dimana saja. Sistem kerja dari rancangan mobil robot yang dirancang, ketika mobil robot memberi perintah, maka perintah tersebut akan disandingkan atau dibandingkan, dan ketika data yang dibandingkan sesuai dengan data yang dicontroller, maka sistem akan berjalan sesuai dengan data atau perintah tadi. Untuk setiap modul, menggunakan tegangan $5 \mathrm{~V}$, sedangkan untuk motor DC, menggunakan tegangan eksternal sebesar 7.4 VDC.

Kata Kunci: Mobil robot, controller arduino, google voice.

\section{PENDAHULUAN}

Perkembangan teknologi elektronika saat ini semakin berkembang, dilihat dari semakin kecilnya komponen yang digunakan dalam satu sistem, atau dilihat dari sudah diaplikasikannya komponen
SMD (Surface mount Device) dan SMT (Surface mount technology). Dengan berkembangnya teknkologi dibidang elektronika, maka tidak dimungkinkan lagi pengaplikasian suatu sistem memerlukan tempat dan ukuran yang luas. Seperti pengaplikasian sistem 
DOI: https://doi.org/10.33330/jurteksi.v6i1.396

Available online at http://jurnal.stmikroyal.ac.id/index.php/jurteksi

mobil robot yang menggunakan IC Driver dari Mini victor yang menggunakan komponen SMD.

Robot merupakan sebuah unit baik berupa mekanikal atau fisikal maupun virtual yang memiliki kecerdasan. Berdasarkan dari segi bentuk, robot mobil merupakan bentuk robot yang dapat secara dinamis berpindah tempat dari satu titik ke titik lainnya [1].

Banyak penelitian yang membahas tentang pengembangan mobil robot, seperti yang dilakukan oleh Partaonan harahap dan kawan kawan. Dalam penelitian yang mereka lakukan, membuat sebuah mobil robot yang dapat dikendalikan untuk melakukan kegiatan memotong rumput [2]. Penelitian yang hampir sama juga dilakukan oleh boi manggala houtagao, dengan judul Sistem pengendalian robot pemotong rumput menggunakan smart phone. Sistem kendali robot yang dia rancang, memanfaatkan perintah dari android dan ultrasonic. Sistem kerja dari robot yang dirancang, berfungsi sebagai pemotong rumput dan menggunakan satu perintah [3].

Penelitian yang akan dilakukan yaitu, merancang mobil robot dengan menggunakan driver mini victor L298, yang merupakan sebagian dari modulnya menggunakan komponen SMD. Selain itu, mobil robot yang akan dirancang, juga akan diberi dua perintah dari android, baik perintah dari google voice maupun dari button android.

\section{Arduino}

Arduino dikatakan sebagai sebuah platform dari physical computing yang bersifat open source. Perlu dipahami bahwa kata "platfoarm" disini adalah sebuah pilihan kata yang tepat. Arduino tidak hanya sekedar sebuah alat pengembangan, tetapi ini adalah kombinasi dari hardware, bahasa pemrograman dan integrated Development Environment (IDE) yang canggih [4].

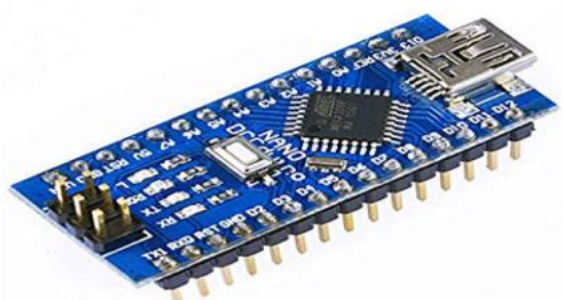

Gambar 2.1 Kontruksi Arduino jenis Nano

Arduino juga memiliki jenis yang berbeda beda, dilihat dari board, ic, jumlah pin dan lainnya. Arduino uno R3 jenis arduino yang umum digunakan dan cocok untuk pemula. Arduino uno R3 juga lebih cocok digabungkan dengan object eksternal laiinya seperti, sensor, actuator, shield dn modul [5].

\section{Motor DC}

Sesuai dengan namanya, motor dc adalah jenis motor yang dikendalikan searah atau DC (direct current). motor ini memiliki dua kabel, satu kabel dihubungkan ke tegangan positif, dan kabel kedua dihubungkan ke ground. kabel yang ketegangan positif boleh yang mana saja. Arah putaran rotor (bagian motor yang berputar) ditentukan oleh kabel yang terhubung ke tegangan positif [6].

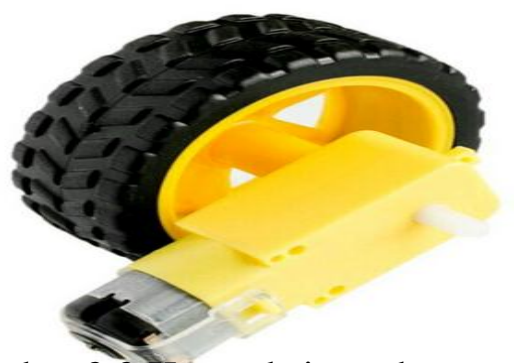

Gambar 2.2 Kontruksi gearbox pada motor DC 
Berdasarkan prinsip kerja dari motor DC, yang dicetuskan oleh michael farraday, mengatakan ketika pada bagian rotor atau kumparan, yang dialiri arus listrik dari baterai atau sumber didekatkan medan magnet, maka pada kumparan atau rotor akan muncul gaya dorong yang akan membuat kumparan berputar.

\section{Mini Victor L298n}

IC L298 sebenarnya menggunakan prinsip jembatan - $\mathrm{H}$, untuk memungkinkan arah putaran motor bisa ditentukan. Prinispnya ditunjukan pada gambar 2.3, dengan menggunakan prinisp ini, sebenarnya dua relai bisa digunakan untuk mengatur arah putaran motor. Namun kelemhannya, relai tidak adapat digunakan untuk mengatur kecepatan motor.

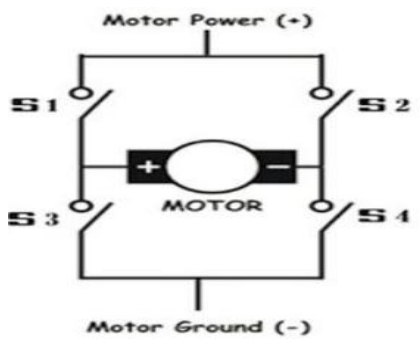

Gambar 2.3 Prinisp jembatan H untuk mengatur putaran motor

Modul L298n, modul ini dapat digunakan untuk mengatur arah putaran dua motor dc.

1. pin Enable $A$, input 1, dan input 2 digunakan untuk mengatur motor DC yang terhubung ke ouput 1 dan output 2.

2. pin EnableB, input 3 dan input 4 digunakan untuk mengatur motor DC yang terhubung ke output 3 dan output.

Tabel 2.1 Hubungan pengontrolan motor DC melalui Mini victor L298n

\begin{tabular}{|c|c|c|c|}
\hline $\begin{array}{c}\text { Enable } \\
\text { A }\end{array}$ & $\begin{array}{c}\text { Input } \\
1\end{array}$ & Input 2 & Keterangan \\
\hline$>0$ & 0 & 1 & $\begin{array}{c}\text { Berputar } \\
\text { satu arah }\end{array}$ \\
\hline$>0$ & 0 & 0 & $\begin{array}{c}\text { Berputar } \\
\text { ke arah } \\
\text { lain }\end{array}$ \\
\hline$>0$ & 0 & 1 & $\begin{array}{c}\text { Berhenti } \\
\text { berputar }\end{array}$ \\
\hline$>0$ & 0 & 0 & Berhenti \\
\hline 0 & - & - & $\begin{array}{c}\text { Motor } \\
\text { tidak } \\
\text { berputar }\end{array}$ \\
\hline
\end{tabular}

\section{Modul bluetooth HC-05}

Bluetooth adalah salah satu bentuk komunikasi data secara nirkabel berbasis frekwensi radio. Penggunaan utama dari modul Bluetooth ini adalah menggantikan komunikasi serial menggunakan kabel. Bluetooth terdiri dari dua jenis perangkat, yaitu Master (pengirim data) dan Slave (penerima). Modul HC-06 dari produsen koneksi secara default diset di kecepatan 9,600 bps (bisa dikustomisasi antara 1200 bps hingga 1,35 Mbps). Modul HC-06 hanya bisa berperan sebagai slave device, module selain modul bluetooth HC-06 ada modul Bluetooth HC- 05, modul ini dapat berperan juga sebagai bluetooth master device ataupun slave, secara default slave.

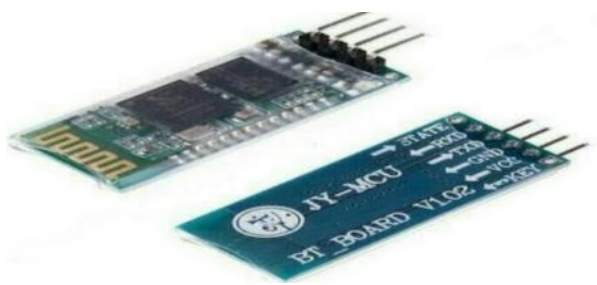

Gambar 2.4 Kontruksi Modul bluetooth HC-05

\section{Android}

Android Merupakan sebuah sistem operasi yang berbasis Linux untuk 
DOI: https://doi.org/10.33330/jurteksi.v6i1.396

Available online at http://jurnal.stmikroyal.ac.id/index.php/jurteksi

telepon seluler seperti telepon pintar dan komputer tablet. Android menyediakan platform terbuka bagi para pengembang untuk menciptakan aplikasi mereka sendiri untuk digunakan oleh bermacam peranti bergerak. Android pada alat yang kami gunakan berfungsi sebagai perekam serta tempat menyimpan hasil rekaman dan android ini juga memudahkan kami dalam hal memprogram yang disambungkan dengan WP3A [7].

\section{Software Pendukung Penelitian Arduino.ide}

IDE itu merupakan kependekan dari Integrated Developtment Enviroenment, atau secara bahasa mudahnya merupakan lingkungan terintegrasi yang digunakan untuk melakukan pengembangan. Disebut sebagai lingkungan karena melalui software inilah Arduino dilakukan pemrograman untuk melakukan fungsifungsi yang dibenamkan melalui sintaks pemrograman. Arduino menggunakan bahasa pemrograman sendiri yang menyerupai bahasa C. Bahasa pemrograman Arduino (Sketch) sudah dilakukan perubahan untuk memudahkan pemula dalam melakukan pemrograman dari bahasa aslinya. Sebelum dijual ke pasaran, IC mikrokontroler Arduino telah ditanamkan suatu program bernama Bootlader yang berfungsi sebagai penengah antara compiler Arduino dengan mikrokontroler.

Arduino IDE dibuat dari bahasa pemrograman JAVA. Arduino IDE juga dilengkapi dengan library $\mathrm{C} / \mathrm{C}++$ yang biasa disebut Wiring yang membuat operasi input dan output menjadi lebih mudah. Arduino IDE ini dikembangkan dari software Processing yang dirombak menjadi Arduino IDE khusus untuk pemrograman dengan Arduino.

\section{App Inventor}

App Inventor 2 (AI2) merupakan IDE generasi kedua dari App Inventor yang dikelola oleh Massachusetts Institute of Technology (MIT). AI2 berbasis cloud yang diakses menggunakan internet browser. Masuk kategori dalam visual programming, AI2 menggunakan block puzzle yang disusun untuk menjadi rangkaian kode (Gambar $1)$.

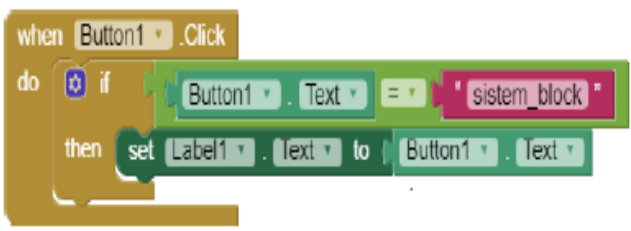

Gambar 2.5 Block puzzle dalam Ai2 Inventor

AI2 memiliki 3 bagian utama, Component Designer, Block Editor dan Android Device yang digunakan untuk pengujian. Pengujian bisa menggunakan emulator maupun perangkat sebenarnya. Untuk perangkat sebenarnya bisa dihubungkan melalui jaringan wireless dan menggunakan USB [5].

\section{HASIL DAN PEMBAHASAN}

Berdasarkan pengujian yang dilakukan untuk hardware berupa modul, dan untuk software berupa aplikasi, maka didapati hasil dari penelitian bahwa susunan atau gabungan hardware yang membentuk suatu sistem mobil robot dengan menggunakan mini victor L298n, dapat diberi perintah dengan menggunakan dua perintah dari android.

Gambar 3.1 (a) Menunjukan diagram alir rancang bangun hardware mobil robot, dan gambar 3.1 (b), menjelaskan 
DOI: https://doi.org/10.33330/jurteksi.v6i1.396

Available online at http://jurnal.stmikroyal.ac.id/index.php/jurteksi

diagram alir rancang bangun software mobil robot.

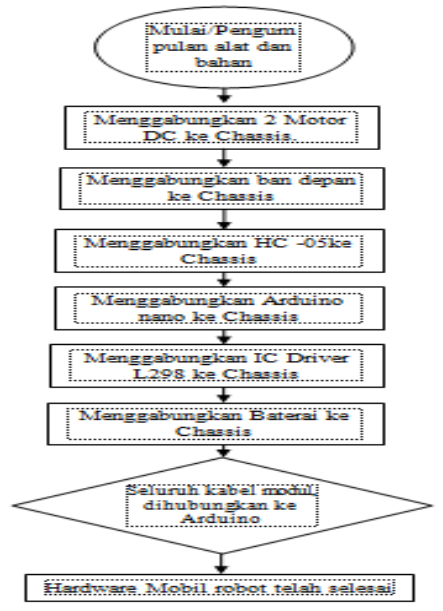

Diagram alir rancang hardware mobil robot dengan driver mini victor L298

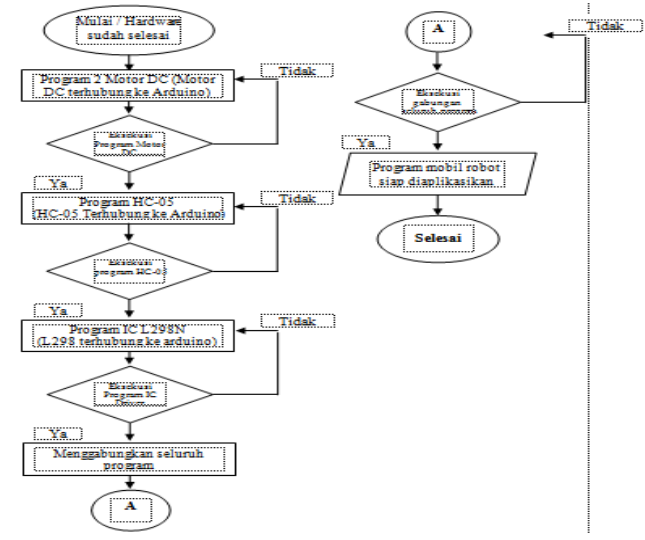

Gambar diagram alir rancang bangun software mobil robot

Gambar 3.1 Diagram alir rancangan hardware dan software mobil robot dengan dua perintah

Setelah diaplikasikannya diagram alir rancang bangun hardware mobil robot, maka dilakukan pengujian pertiap modul sehingga didapat hasil pengujian pertiap modul :

\section{Pengujian Modul}

Pengujian Arduino Dengan Virtual Mini driver L298n
Adapun hasil keterangan pengujian tegangan arduino dengan virtual mini yang didapat, ditunjukan pada tabel 3.1

Tabel 3.1 Hasil pengujian tegangan arduino dengan mini virtual driver L298

\begin{tabular}{|l|l|l|l|}
\hline \multicolumn{1}{|c|}{ V Arduino } & Status & \multicolumn{1}{c|}{$\begin{array}{c}\text { Mini } \\
\text { Victor }\end{array}$} & Keterangan \\
\hline $\begin{array}{l}3.3 \\
\text { VDC/internal }\end{array}$ & HIGH & Dingin & Bekerja \\
\hline $\begin{array}{l}\text { 5 VDC } \\
\text { internal }\end{array}$ & HIGH & Sedang & Bekerja \\
\hline 7.4 Eksternal & HIGH & Panas & Bekerja \\
\hline
\end{tabular}

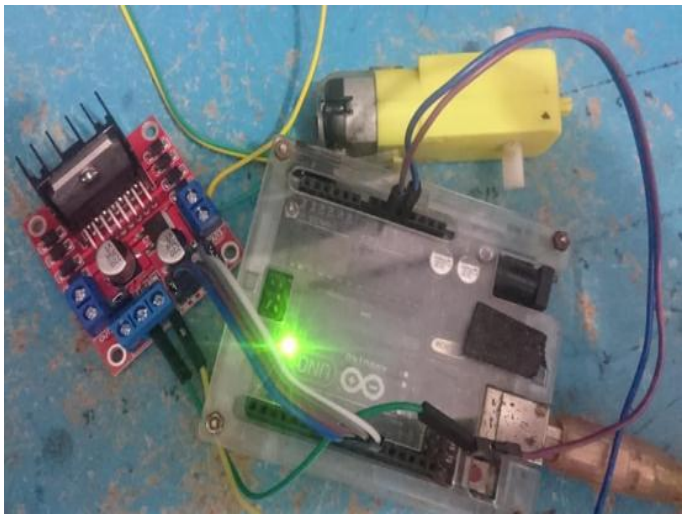

Gambar 3.2 Pengujian mini victor L298

\section{Pengujian virtual mini L298 dengan motor DC 5V}

Adapun hasil keterangan pengujian tegangan yang didapat dari motor Dc dan virtual mini, ditunjukan pada tabel 3.2

Tabel 3.2 Hasil pengujian virtual mini dengan motor DC 5V

\begin{tabular}{llcl}
\hline \multicolumn{1}{c}{ V Arduino } & Motor & $\begin{array}{c}\text { Mini } \\
\text { Victor }\end{array}$ & Keterangan \\
\hline 3.3 & Tidak & Dingin & Tidak \\
VDC/internal & bergerak & & Bekerja \\
\hline 5 VDC internal & Pelan & Sedang & Bekerja \\
\hline 7.4 & Standart & Panas & Bekerja \\
VDC/Eksternal & & & \\
\hline
\end{tabular}


DOI: https://doi.org/10.33330/jurteksi.v6i1.396

Available online at http://jurnal.stmikroyal.ac.id/index.php/jurteksi

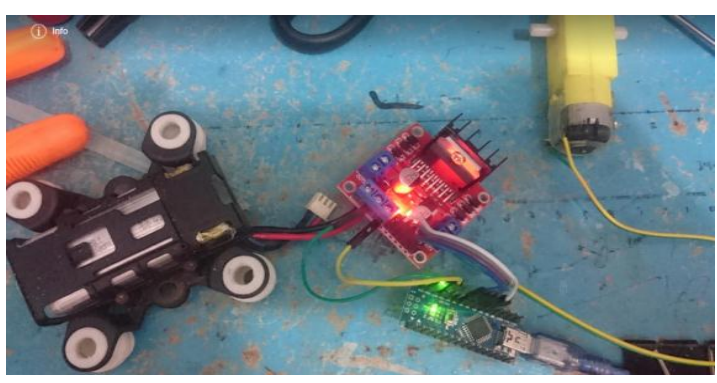

Gambar 3.3 Pengujian motor DC

\section{Pengujian arduino dengan modul HC-} 05

Adapun hasil keterangan pengujian tegangan yang didapat,antara arduino dengan hc-05 ditunjukan pada tabel 3.3

Tabel 3.3 Hasil pengujian V Arduino dengan $\mathrm{HC}-05$

\begin{tabular}{|c|c|c|}
\hline V Arduino & Status & Keterangan \\
\hline $\begin{array}{l}3.3 \\
\text { VDC/intern } \\
\text { al }\end{array}$ & $\begin{array}{l}\text { Alamat } \\
\text { tidak } \\
\text { tampil }\end{array}$ & $\begin{array}{c}\text { Not } \\
\text { connected }\end{array}$ \\
\hline $\begin{array}{l}5 \quad \text { VDC } \\
\text { internal }\end{array}$ & $\begin{array}{l}\text { Alamat } \\
\text { tampil }\end{array}$ & connected \\
\hline
\end{tabular}

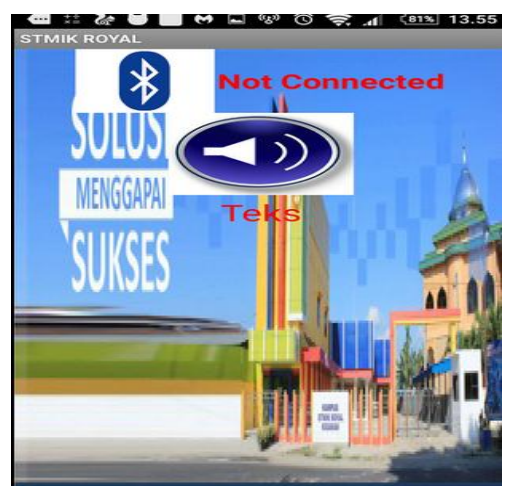

(a) Software google voice mobil robot

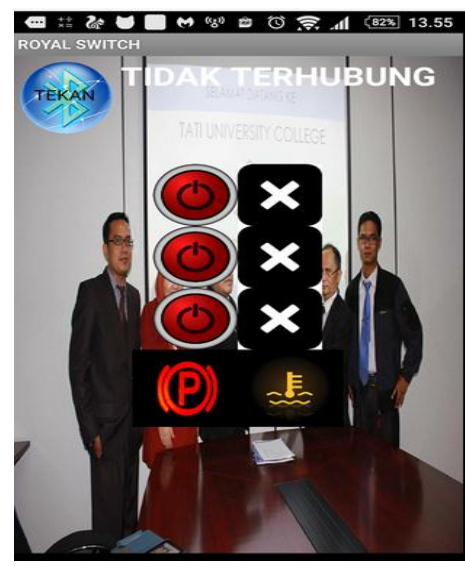

(a) Software google voice mobil robot

Gambar 3.4 Tampilan software mobil robot dengan dua perintah

\section{Pengujian Mobil Robot Keseluruhan}

Adapun hasil keterangan pengujian keseluruhan perintah untuk mobil robot, dengan dua perintah google voice, ditunjukan pada tabel 3.4

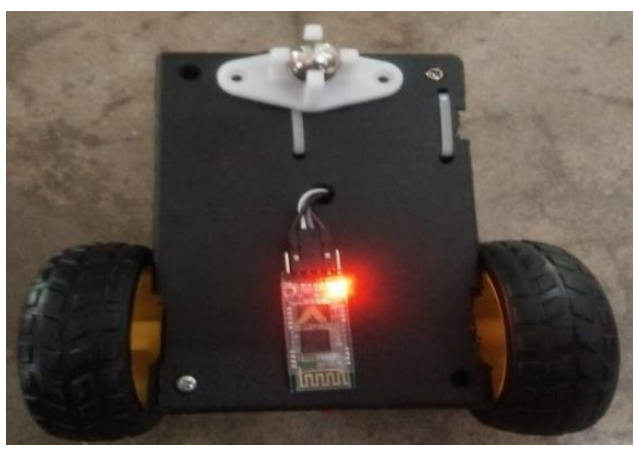

Gambar 3.4 Tampilan mobil robot dengan dua perintah 
Vol. VI No. 1, Des 2019, hlm. 51 - 58

DOI: https://doi.org/10.33330/jurteksi.v6i1.396

Available online at http://jurnal.stmikroyal.ac.id/index.php/jurteksi

Tabel 3.4 Hasil pengujian mobil robot keseluruhan

\begin{tabular}{|c|c|c|c|}
\hline \multicolumn{4}{|c|}{ Google voice } \\
\hline Perintah & Modul & Status Analog & $\begin{array}{l}\text { Status } \\
\text { Digital }\end{array}$ \\
\hline Maju & $\begin{array}{l}\text { Motor } 1 \\
\text { Motor } 2 \\
\text { Motor A } \\
\text { Motor B }\end{array}$ & $\begin{array}{c}130 \\
130 \\
0 \\
0\end{array}$ & $\begin{array}{l}\text { Low } \\
\text { Low } \\
\text { Low } \\
\text { Low }\end{array}$ \\
\hline Mundur & $\begin{array}{l}\text { Motor 1 } \\
\text { Motor 2 } \\
\text { Motor A } \\
\text { Motor B }\end{array}$ & $\begin{array}{c}0 \\
0 \\
130 \\
130 \\
\end{array}$ & $\begin{array}{l}\text { Low } \\
\text { Low } \\
\text { Low } \\
\text { Low }\end{array}$ \\
\hline Kiri & $\begin{array}{l}\text { Motor } 1 \\
\text { Motor } 2 \\
\text { Motor A } \\
\text { Motor B }\end{array}$ & $\begin{array}{c}130 \\
0 \\
0 \\
0\end{array}$ & $\begin{array}{l}\text { Low } \\
\text { Low } \\
\text { Low } \\
\text { Low }\end{array}$ \\
\hline Kanan & $\begin{array}{l}\text { Motor 1 } \\
\text { Motor } 2 \\
\text { Motor A } \\
\text { Motor B } \\
\end{array}$ & $\begin{array}{c}0 \\
130 \\
0 \\
0 \\
\end{array}$ & $\begin{array}{l}\text { Low } \\
\text { Low } \\
\text { Low } \\
\text { Low }\end{array}$ \\
\hline Berhenti & $\begin{array}{l}\text { Motor 1 } \\
\text { Motor } 2 \\
\text { Motor A } \\
\text { Motor B }\end{array}$ & $\begin{array}{l}0 \\
0 \\
0 \\
0\end{array}$ & $\begin{array}{l}\text { Low } \\
\text { Low } \\
\text { Low } \\
\text { Low }\end{array}$ \\
\hline \multicolumn{4}{|c|}{ Perintah Button Android } \\
\hline Perintah & Modul & Status Analog & Status Digital \\
\hline A & $\begin{array}{l}\text { Motor 1 } \\
\text { Motor } 2 \\
\text { Motor A } \\
\text { Motor B }\end{array}$ & $\begin{array}{l}0 \\
0 \\
0 \\
0\end{array}$ & $\begin{array}{l}\text { HIGH } \\
\text { HIGH } \\
\text { LOW } \\
\text { LOW }\end{array}$ \\
\hline B & $\begin{array}{l}\text { Motor 1 } \\
\text { Motor } 2 \\
\text { Motor A } \\
\text { Motor B }\end{array}$ & $\begin{array}{l}0 \\
0 \\
0 \\
0\end{array}$ & $\begin{array}{l}\text { LOW } \\
\text { LOW } \\
\text { HIGH } \\
\text { HIGH }\end{array}$ \\
\hline 1 & $\begin{array}{l}\text { Motor 1 } \\
\text { Motor } 2 \\
\text { Motor A } \\
\text { Motor B }\end{array}$ & $\begin{array}{l}0 \\
0 \\
0 \\
0\end{array}$ & $\begin{array}{l}\text { HIGH } \\
\text { LOW } \\
\text { LOW } \\
\text { LOW }\end{array}$ \\
\hline 2 & $\begin{array}{l}\text { Motor 1 } \\
\text { Motor } 2 \\
\text { Motor A } \\
\text { Motor B }\end{array}$ & $\begin{array}{l}0 \\
0 \\
0 \\
0\end{array}$ & $\begin{array}{l}\text { LOW } \\
\text { HIGH } \\
\text { LOW } \\
\text { LOW }\end{array}$ \\
\hline 123 & $\begin{array}{l}\text { Motor 1 } \\
\text { Motor } 2 \\
\text { Motor A } \\
\text { Motor B }\end{array}$ & $\begin{array}{l}0 \\
0 \\
0 \\
0\end{array}$ & $\begin{array}{l}\text { LOW } \\
\text { LOW } \\
\text { LOW } \\
\text { LOW }\end{array}$ \\
\hline $\mathrm{ABC}$ & $\begin{array}{l}\text { Motor } 1 \\
\text { Motor } 2 \\
\text { Motor A } \\
\text { Motor B }\end{array}$ & $\begin{array}{l}0 \\
0 \\
0 \\
0\end{array}$ & $\begin{array}{l}\text { LOW } \\
\text { LOW } \\
\text { LOW } \\
\text { LOW }\end{array}$ \\
\hline
\end{tabular}


DOI: https://doi.org/10.33330/jurteksi.v6i1.396

Available online at http://jurnal.stmikroyal.ac.id/index.php/jurteksi

\section{SIMPULAN}

1. Perintah yang dikirimkan bisa menggunakan dua perintah, yaitu google voice dan button android, tetapi untuk akses terhubung, hanya bisa dihubungkan ke satu perintah.

2. Ketika software yang digunakan adalah google voice, maka perintah motor DC pada mobil robot, menggunakan perintah analaogWrite, dengan kecepatan desimal 130. Sedangkan jika perintah yang digunakan menggunakan software button android, maka perintah motor DC menggunakan perintah pin digital, yaitu digitalWrite, hanya mengenal high dan low.

\section{DAFTAR PUSTAKA}

[1] Abdul kadir. Pemrograman arduino menggunakan ardublock, tuntunan praktis mempelajari proyek proyek elektronika berbasis arduino menggunakan bahasa pemrograman visual ardublock. 2017. Andi. Yogyakarta

[2] Dendy dan kawan kawan. Rancang Bangun Alat dan Aplikasi untuk para Penyandang Tunanetra Berbasis Smartphone Android. Vol 2. no 1. ISSN: 2477-698X.2016

[3] Hendy Djay Siswaja. Prinsip kerjadan klasifikasi robot. Vol 7. no 3. Media Informatika. hal 147-157.

[4] Hutagaol dan boi manggala. istem pengendalian rogot pemotong rumput menggunakan smartphone android. Repositori usu 2018.

[5] Mada Sanjaya.Panduan praktis membuat robot cerdas menggunakan arduino dan matlab. 2016. Andi. Yogyakarta

[6] Partaonan Harahap. Perancangan Alatpemotong rumput otomatis berbasis arduino uno memakai joystick.Seminar nasional teknik elektro. 2018. ISBN 978-602-869234-2

[7] Ricki Ananda. 40 Project robotik dan aplikasi android. 2016. deepublish. Yogyakarta 